\title{
Western solidarity with Pussy Riot and the Twittering of cosmopolitan selves
}

\author{
FrankWeij (weij@eshcc.eur.nl) \\ Department of Art and Culture Studies (ESHCC), Erasmus University Rotterdam \\ Pauwke Berkers (berkers@eshcc.eur.nl) \\ Department of Art and Culture Studies (ESHCC), Erasmus University Rotterdam
}

Jiska Engelbert (engelbert@eshcc.eur.nl)

Department of Media and Communication (ESHCC), Erasmus University Rotterdam

\begin{abstract}
This article aims to explain the widespread attention to contemporary protesting artists among Western audiences by focusing on the case of Pussy Riot. Social movement scholarship provides a first step into understanding how Pussy Riot legitimately protests Russian politics through its punk performances. It then turns to the concept of cosmopolitanism as a performance in everyday life to explain Pussy Riot's appeal among Western audiences. By collecting and analyzing 9001 tweets through a thematic hashtag analysis and topic modeling, this article analyzes how audiences talk about Pussy Riot and shows how Twitter affords users to perform cosmopolitan selves by sharing their ideas and experiences on Pussy Riot with others. Although we distinguish between four types of cosmopolitan selves, the results clearly show Pussy Riot is mainly reflected upon in a media context: Twitter users predominantly talk about Pussy Riot's media appearances rather than readily engage with its explicit political advocacy.
\end{abstract}




\section{Introduction}

For decades, artists - particularly pop culture celebrities - have been raising awareness for distant humanitarian issues, ranging from pop musicians like Bob Geldof organizing the Live Aid concert to Hollywood actors like Angelina Jolie becoming United Nations ambassadors. These projects, however, operate non-politically as they focus on humanitarian crises mainly in the Global South within - instead of in opposition to - existing Western political institutions. As such, media outlets can easily reconcile between these non-explicitly political projects and the dominant commercial media logic (Rossman, 2004) as media consumers readily engage with such de-politicized news events on issues of humanitarian violations (Jabri, 2007).

However, in an era of global cultural exchange, we witness the rise of a different type of protesting artist of which the Russian activist group Pussy Riot is one of the most visible examples. Firstly, contrary to politically engaged celebrity artists, these protesting artists are not necessarily famous prior to their political advocacy. Secondly, they explicitly challenge and criticize the practices of domestic political institutions. Drawing on the (Western) punk genre, Pussy Riot employs public performances with explicit lyrics to convey their critique on Putin's regime and traditional domestic institutions, such as the Russian Orthodox Church. Thirdly, they often experience severe criticism or even legal repercussions within their own country, while receiving broad support from international media outlets and Western media consumers. Indeed, Pussy Riot's confrontational performances have spawned fierce reactions from Russians in general and Russian political institutions in particular. In 2012, after performing their widely known Punk Prayer in one of the main Russian Orthodox cathedrals in Moscow, three members were arrested. The following trial received global media coverage as the Punk Prayer video had gone viral on YouTube. ${ }^{1}$

In this article we address this supposed paradox of the widespread attention among de-politicized Western audiences for explicit political advocacy. We argue that such media consumption affords cosmopolitan expressions as Western audiences engage with (i) mediatized protests of artists who (ii) explicitly address political issuesthat revolve largely 
around the Western core value of human rights, as a way to demonstrate their engagement with distant others. This is particularly visible on social media where individuals can share ideas in everyday life (Bennett and Segerberg, 2012). Through an analysis of Twitter data, we will explore how Western audiences talk about Pussy Riot and subsequently analyze in what ways a cosmopolitan self is performed through tweets. The central research question, therefore, is: In what ways does Pussy Riot's mediated political advocacy afford Western audiences to perform cosmopolitan selves on Twitter?

\section{Social movements and the legitimacy of Pussy Riot}

Unlike most popular culture celebrities, protesting artists - here: the members of Pussy Riot often did not enjoy international or even national fame prior to their political advocacy. As such, their legitimacy as political actors is not based on their ability to reach many people per se (Chouliaraki, 2012). Similar to social movements - collectives formed by groups that feel excluded and therefore attempt to mobilize non-institutionalized political influence to achieve their collective interests (McAdam, 1982: 20), protesting artists achieve legitimacy in the political field when they are recognized and valued as representing an underrepresented social group (Tilly, 1984: 306).

Regarding its political program, Pussy Riot can be seen to represent those groups that it feels to be repressed by the Russian government, particularly LGBTQ and feminists (Prozorov, 2013). Pussy Riot, then, as a collective of protesting artists has political legitimacy by making the demands of these groups publicly visible - without necessarily being their 'official' spokesperson. While social movement scholarship is able to explain how artists in social movements gain political legitimacy, it does not offer an explanation for the paradox of the appeal of Pussy Riot, that is, the widespread attention among (arguably) de-politicized Western audiences for their explicit political advocacy (Della Porta, Kriesi and Rucht, 2009).

\section{Performing cosmopolitan selves}


One way to account for this paradox is by drawing on the concept of cosmopolitanism. This dynamic concept entails the ideal of global citizenship (Beck and Sznaider, 2006), by which individuals overcome their locality to become "citizens of the world" (Calhoun, 2002). To be cosmopolitan, then, requires the expression of a particular lifestyle through which people enter a global sphere of cultural ideas and experiences (Hannerz, 2000; Jenkins, 2004). If we understand cosmopolitanism in this way, it should be analyzed as a performance and social practice (Weenink, 2008) that range from consuming global cultural products - like ethnic food or foreign art (Calhoun, 2002) - to more subtle practices that involve solidarity with foreign political struggles (Mihelj, Van Zoonen and Vis, 2011). As such, they are a way of presenting an idealized self to others (Goffman, 1959), by displaying one's solidarity with distant others through media consumption (Firat and Dholakia, 1998) - consuming as integration (Holt, 1995).

Pussy Riot's political advocacy revolves around deeply rooted Western values such as human rights and freedom of speech. Such protests, when mediatized, could easily afford expressions of cosmopolitanism on the part of Western audiences: they display solidarity with distant others by demonstrating support for those who are fighting for Western core values. Cosmopolitanism is therefore communicative: it is a performed lifestyle that is articulated by listening to the distant other and being listened to as the other (Mihelj, Van Zoonen and Vis, 2011).These communicative processes, through which the expression of cosmopolitanism is afforded, are especially salient in media consumption on a micro level. Within the online environment of social media, individuals share personalized ideas about political issues with others rather than explicitly and collectively act on them (Bennett and Segerberg, 2012). As a microblogging service in which people can engage in conversation with others (Hermida, 2010) - consuming as play (Holt, 1995), Twitter provides an interesting empirical avenue to study how audiences talk about foreign political struggles and communicate their cosmopolitan selves to others both far away and close by. Instead of being undermined by a lack of responsiveness (Della Porta, Kriesi and Rucht, 2009), then, Pussy Riot's explicit 
political advocacy possibly gains substantial attention by affording the performance of cosmopolitanism on the part of Western audiences.

In this article, we distinguish between two primary contexts in which Twitter users present cosmopolitan selves. First, audiences may demonstrate to have consumed media material that depoliticizes Pussy Riot's political activism (Jabri, 2007) by fitting it in a commercial media logic (Rossman, 2004). Here the focus of users is mainly on the mediatization of Pussy Riot. Second, in contrast, a more political context is observable when Twitter users demonstrate to pay attention to Pussy Riot's explicit political advocacy. Here users might make use of Twitter's infrastructure to express solidarity with others through connective action (Bennett and Segerberg, 2012), rather than merely depoliticizing Pussy Riot's political advocacy. Yet, besides this crude dichotomy of contexts, we know very little about the different cosmopolitan selves protesting artists - like Pussy Riot - afford.

\section{Data and methods}

Twitter is a social media platform that has become the most ubiquitous and popular microblogging application (Arceneaux and Schmitz Weiss, 2010). These platforms are characterized by short and instantly deliverable textual messages to a group of subscribed users (Hermida, 2010). Twitter users range from individual people to news network stations (Broersma and Graham, 2012), demonstrating its wide dispersion among institutionalized news media. Indeed, Twitter has proven to be an important platform when it comes to the dissemination of newsworthy events (Larsson and Moe, 2011). Twitter users can post short text messages (maximum of 140 characters) that are called tweets. These messages are not merely one-off statements but often involve more extensive conversations (Honeycutt and Herring, 2009) as users - and their followers - can react to and "retweet" each other's Twitter messages.

For this study, a large sample of tweets was collected by gaining access to Twitter's Application Programming Interface (API) for public streams. Through a Python computer script, Twitter messages that contained the words "Pussy Riot" were saved to a single text 
file. Through this method, the content of the tweet itself as well as information about the user and his or her Twitter profile (e.g. the user's name, location, etc.) that is embedded in a tweet was gathered in a single line of code. We ran this computer script over the course of four days from February $3^{\text {rd }}$ to February $6^{\text {th }}$ in 2014 . This particular period was chosen because it concerned a short period in which Pussy Riot's two main members appeared in several mediatized events and news media in various Western countries. These four days, therefore, rendered a good opportunity to collect a relatively large amount of data on active Twitter discussions involving Pussy Riot. This process resulted in a sample of more than twenty thousand tweets. For the scope of this paper, only tweets in English ${ }^{2}$ were included, yielding a sample of 9,001 tweets as our units of analysis, from a total of 5,692 unique users.

To measure the ways in which cosmopolitanism is performed in tweets, two modes of analysis were chosen. First, a thematic analysis of the hashtags enables us to discover manifest themes in Twitter messages. Hashtags have become a convention on Twitter to highlight topical discussions (Bruns and Burgess, 2012) and thus are meaningful as they appropriate particular themes. The second mode of analysis, topic modeling, is an innovative method to discover hidden themes - meaningful categories, or "topics" - in large bodies of text. These models uncover clusters of words that "occur in documents together more frequently than one would expect by chance" (DiMaggio, Nag and Blei, 2013: 578). This paper uses the software program Mallet, which is a topic model that uses the Latent Dirichlet Allocation - or LDA (Blei, Ng and Jordan, 2003). This is an algorithm that assumes a relational approach to texts in the sense that the meaning of words emerges from the different semantic relations among them (Mohr and Bogdanov, 2013). As a result, instead of looking at isolated words, topic modeling discovers latent structures in a collection of textual documents and shows us more qualitatively (albeit on a large scale) what themes emerge from the vast body of tweets.

\section{Thematic hashtag analysis: mediatized events and institutionalized politics}


The first analysis concerns the retrieval of latent themes among the hashtags that Twitter users have used when tweeting about Pussy Riot. Out of the total sample of 9,001 tweets about half (49\%) of those contained at least one hashtag (ranging up to a maximum of twelve hashtags in one single tweet), resulting in a total number of 7,176 hashtags. ${ }^{3}$ Table 1 displays the most prevailing themes along with several illustrative examples.

-- Table 1 about here --

First, the themes that have been used most often contain hashtags related to a media context ( $22 \%$ in total), indicating that Twitter users pay considerable attention to those moments in which Pussy Riot is incorporated into the Western commercial media logic. On the one hand, most users either share their (mediatized) attendance to 'events' (17\%) such as the Human Rights Concert in New York, or link Pussy Riot to a celebrity (3\%). As such, they focus on global popular culture and demonstrate a pop culture cosmopolitan self. On the other hand, an albeit small proportion of hashtags pertains to serious news media such as the New York Times or the Guardian. By using hashtags to refer to such news media, Twitter users present a self that consumes more serious, highbrow news media platforms. Here, then, we see a highbrow cosmopolitan self.

Second, only eight percent of the hashtags refer directly to politics, but do not seem to touch upon those matters that are more directly central to Pussy Riot's political advocacy. Rather, these hashtags remain largely in the domain of institutionalized politics with references to Putin, Obama, ambassadors, the UN and other similar institutional political issues and actors. Such an institutionalized political context shows one's openness to foreign political affairs. These users display what we will call a political cosmopolitan self. Hashtags that do suggest an immediate engagement with Pussy Riot's political advocacy are less frequently used on Twitter. While there is perhaps still a fair amount of hashtags (7\%) devoted to various human rights issues, calls for activism (1\%) or support (1\%) remain minor 
discussion topics. ${ }^{4}$ This second type of cosmopolitanism within a political context will be referred to as an activist cosmopolitan self.

\section{Topic modeling}

The second analysis leaves room to more qualitatively study the way in which Twitter users talk about Pussy Riot. By looking at prevailing words in their semantic contexts rather than solely looking at isolated hashtags, we can more readily assess the hidden themes that arise from this body of tweets. Ten topics were requested as this amount yielded a good fit without displaying too many or too little themes in one topic. Table 2 shows these topics, each along with the thirteen most occurring terms per topic (on average all tweets contained thirteen words). For reasons of clarity, the topics are ordered on a continuum. On the left are topics that more strongly convey a media context, illustrated by both the number and position - the higher the rank (1-13), the higher the association frequency - of words that refer to a media contexts. On the right are the topics that more strongly convey a political context.

-- Table 2 about here --

\section{Pussy Riot tweets in a media context}

The first five topics clearly address the mediatized events in which Tolokonnikova and Alyokhina appeared as these events (Amnesty concert and the televised Colbert Report ) are highly ranked, indicating that these words occur most frequently within the respective topics. The main differences within these topics, however, are in terms of the context in which these events are discussed. In Topic 1 most words only superficially touch upon the Amnesty event and mainly address Pussy Riot's association with Madonna and other stars during this event. The tweet below, in which Topic 1 is probabilistically most prevalent, is indicative of this: 
A tweet like this immediately reminds us of Chouliaraki's (2012) relatively pessimistic view of post-humanitarianism, that is, distant struggles gain attention only in the context of a Western popular media logic. The tweet does not tell us anything about what was discussed during the appearance of Pussy Riot at the event, but rather that it was worthwhile to be present as various celebrities and stars introduced and discussed Tolokonnikova and Alyokhina and their activist practices. This topic, then, conveys a pop culture cosmopolitan self.

Topic 2, 3, 4 and 5 all involve the interview of Pussy Riot on the Colbert Report, but each in a different context. Topic 2 mainly addresses the issue of the 2014 Olympics which Pussy Riot aimed to boycott but also puts Pussy Riot's visit at the New York Times editorial board central. When we look closer at the tweet in which Topic 2 is most prevalent, we mainly see a highbrow cosmopolitan self occurring as the focus is on the New York Times.

Wish PR would visit our editorial board. RT @nytopinion Pussy Riot visits the NYT editorial board http://t.co/ChUJmySP21

Topic 3 involves the critique Pussy Riot uttered towards Putin on the Colbert Report as a 'shirtless man on a horse' they do not want to lead them into Russia's future. Topic 4 and 5address the issue of imprisonment and the position of gay people in Russion, which were also elaborately discussed during the Colbert interview. Interestinglyrather than talking about such statements, the tweets mainly remain at the level of citing and reiterating what Tolokonnikova and Alyokhina said during mediatized events. Like the first topic, then, these three mostly convey a pop culture cosmopolitan self.

\section{Pussy Riot in a political context}

Topics 6 through 10 can be located within an institutional - but not activist - political context. Topic 6 demonstrates a reference to a mediatized context (the Amnesty event), but most other 
words pertain more to political affairs (e.g. "jail", "Sochi”, "USenvoy", etc.). Below is the tweet in which Topic 6 is most prevalent:

RT@AmbassadorPower: Met some brave troublemakers today \#PussyRiot's @mashaalekhina \& @tolokno came by to discuss their time in jail.

Again, it is a (reiterated) statement that involves Tolokonnikova and Alyokhina's prison experience and their views on solidarity, without immediately framing it in a mediatized context. In other words, the particular tweet in which this topic was most prevalent addresses more readily an explicit political issue Pussy Riot aims to address. The same holds true for topic 7. Below is quoted the tweet in which Topic 7 is most likely to occur:

Happening now: \#PussyRiot takes Brooklyn! Copies of WORDS WILL BREAK CEMENT by Masha Gessen free at Barclay's Center.

This tweet refers to a book that has recently been published on Pussy Riot. Twitter users do not engage with the content of the book but mainly emphasize its availability, associated with Pussy Riot's appearance at the Amnesty concert.

Topics 8, 9 and 10 illustrate a more nuanced picture than the initial thematic hashtag analysis in terms of attention to political issues. Topic 9 in particular demonstrates that when Twitter users talk about Pussy Riot's appearance in the Amnesty event, the issue of imprisonment does gain attention, as is shown by words like "terrible" and "conditions". The tweets in which this topic was most likely to prevail opens with reference to a political actor:

@ AmbassadorPower: I asked \#PussyRiot if they were afraid of prison. Response: No. In prison we could see the terrible conditions.

Nonetheless, as already seen in most other topics, this particular tweet is a reiteration of Pussy Riot's response to a question about their experience in prison. It does not show us how 
Twitter users themselves talk about this issue of imprisonment. The highest ranked words in both Topic 8 and 10 do not contain any direct reference to a media context and at first sight seem to have a more explicit political dimension to them. Both topics more clearly relate to politics, including words such as "rights", "politicians" and "envoys". However, we need a closer look at some of the tweets in which these topics are most prevalent tobetter understand what these words signify.

US and Russian envoys in Pussy Riot spat: Two ambassadors to UN exchange jibes over Russian punk protest http://t.co/WhVYm6320p

A binderful of women, a slew of slit, a clot of clams, a transvaginal of trim, a vulgarity of vaginae, a coven of cunts, a riot of pussy

The two tweets above, in which Topic 8 is most prevalent, at first sight do not seemunrelated. The first one involves a discussion on ambassadors and the political relations between Russia and the United States and remains mostly observational. The second one jokingly refers to Mitt Romney at a 2012 presidential debate when Romney was asked about gender inequality. Thus, both involve politics without readily engaging with the key issues that are central to Pussy Riot.

Pussy Riot urges politicians attending Winter Olympics to publicly criticize human rights abuses during visit http://t.co/e4AQViCXSU

When we look at the abovementioned tweet, Topic 10 clearly involves a discussion on the 2014 Olympics in Russia in relation to human rights issues. From this tweet, it becomes clear that human rights in Russia need attention, since they are claimed by Pussy Riot to be abused and are something to stand up for. However, it does not contain any clear reflections on particular human rights issues (e.g. women rights, gay rights, etc.) for which Pussy Riot aimed to boycott the winter Olympics. To sum up, then, Topics 6 through 10 all convey a 
political cosmopolitan self, as these involve a political context but do not engage with any of Pussy Riot's activism.

\section{Conclusion and discussion}

This paper has sought to better understand the widespread attention from Western audiences to contemporary protesting artists through a case study of Pussy Riot. It addressed in what ways Pussy Riot's mediated political advocacy affords Western audiences to perform cosmopolitan selves on Twitter. The main observation when looking at the ways in which Twitter users talk about Pussy Riot is that the media are strikingly present, while Pussy Riot's explicit political advocacy is strikingly absent. Within both these contexts we have observed two types of cosmopolitan selves. Regarding the first context, users mostly draw on and engage with the mediatized events in which Pussy Riot appeared as well as some of the celebrities with which the group has been associated; here a pop culture cosmopolitan self prevails. Twitter users present to others a self that can be seen as being involved with distant affairs without explicitly engaging with them. Less likely but still observable are those Twitter users that refer to other media platforms - mostly the New York Times - that covered Pussy Riot. These users demonstrated what we referred to as highbrow cosmopolitan self, by showing that they consume and share news on Pussy Riot's media appearances more through quality newspapers rather than popular television shows.

Secondly, a smaller proportion of users focus more on a political context involving Pussy Riot. Here most users emphasize institutional politics, by for example talking about Pussy Riot in the context of geopolitical affairs. These users display a political cosmopolitan self as they mostly remain at the level of institutional politics rather than engaging with Pussy Riot's explicit political advocacy. A very small proportion of users demonstrate an emphasis on activism, mainly observable through hashtag use. They, for example, discuss women's rights in Russia or actively call out for action and thereby perform an activist cosmopolitan self. However, this might be seen as a form of clicktivism (Halupka, 2014) as it involves 
activism by merely reacting to political content rather than by political action in the form of prolonged engagement with particular political issues.

In this sense, Twitter as a social media platform readily affords its users to present cosmopolitan selves that are concerned not so much with actual issues of social justice. Pussy Riot has gained extensive attention, contradicting the lack of responsiveness for foreign and explicit political protests (Della Porta, Kriesi and Rucht, 2009). However, by focusing mainly on Pussy Riot's media appearances, Twitter audiences do display a lack of responsiveness to political advocacy. Even though the media events in which Pussy Riot appeared did not completely depoliticize the group's protests, Twitter audiences' solidarity was primarily expressed by highlighting popular media and celebrities. Openness to distant cultural ideas and experiences, when analyzed more practically rather than theoretically (e.g. Calhoun, 2002; Hannerz, 2000), however, calls for a more nuanced approach: Western audiences can indeed demonstrate this cosmopolitan openness, crucial however are the ways in which they do so (i.e. mediatized rather than political).

The data used for this study covered a period in which Pussy Riot appeared in several media outlets and therefore our results demand some caution. However, including a control period proved to be difficult. First, the amount of Twitter messages was only high at moments in which Pussy Riot appeared in the media, with the exception of news platforms instead of individuals users.Not surprisingly, from our sampling four-day period, the two days in which Pussy Riot appeared at the Colbert Report and the Amnesty concert, respectively, accounted for roughly eighty percent of our sample. Second, splitting our dataset into two sets of little and extensive mediatized attention weakens the topic model, rendering the results less valid. ${ }^{5}$

These limitations, too, illustrate the selective audience attention to Pussy Riot. In addition, although the media events in which Pussy Riot appeared are expected to provide ample room for active discussions on its political advocacy, the results still show that these events turn out to not yield moments in which Western audiences readily engage with Pussy Riot's protests. Rather than providing audiences with ample room for critical reflection, the 
attention to these events shows how audiences focus mostly on what others (particularly prominent media figures such as celebrities) say and what is said on mainstream news media.

In addition, the results show the possibilities and limitations of Twitter as an instrument in presenting an idealized (cosmopolitan) self as well as an object of study. On the one hand, the two modes of analysis adopted in this paper illustrate Twitter's affordances as a platform for self-expressive communicative practices. On the other hand, these findings also seem to suggest that Twitter is perhaps less suited as a platform for audiences to more explicitly engage with political affairs. Indeed, by drawing on Giddens' conception of ontological security Larsson (2013) argues that even in the digital era of social media traditional and routinized norms for political activity still hold sway. Moreover, our sample of Twitter users does not fully represents Western audiences for at least two reason. First, Twitters users are usually relatively young and come from urban areas (Duggan and Brenner, 2013). Second, we included only English-language tweets in our analysis, excluding tweets in other Western languages as French and German. Although the English language was by far the most present language in our sample (including Twitter users from non-Englishspeaking countries), these data preparation choices demand some caution as they can affect the outcome.

Future research should provide a more complete understanding of the appeal of contemporary protesting artists. The scope of this paper excludes analyzing the way in which Pussy Riot itself mediates its political advocacy as well as the way in which media outlets feature Pussy Riot's protests. Furthermore, it should be noted that Western audiences do not form a group that should be located completely outside of contemporary protesting artists' political advocacy; rather, they co-create protests and activism. A more qualitative study of Twitter's political affordances should reveal how the cosmopolitan performances as found in this paper, in which solidarity with Pussy Riot revolves largely around how individuals themselves pay attention to Pussy Riot's media appearances, co-shape political protests. 


\section{References}

Arceneaux N and Schmitz Weiss A (2010) Seems stupid until you try it: press coverage of Twitter, 2006-9. New Media \& Society 12(8): 1262-1279.

Beck U and Sznaider N (2006) Unpacking cosmopolitanism for the social sciences: A research agenda. British Journal of Sociology 57(1): 1-23.

Bennett WL and Segerberg A (2012) The logic of connective action. Information, Communication \& Society 15(5): 739-768.

Blei DM, Ng AY and Jordan MI (2003) Latent dirichlet allocation. Journal of Machine Learning Research 3: 993-1022.

Broersma M and Graham T (2012) Social media as beat. Journalism Practice 6(3): 403-419.

Bruns A and Burgess J (2012) Researching news discussions on Twitter. Journalism Studies 13(5): 801-814.

Calhoun CJ (2002) The class consciousness of frequent travelers: Toward a critique of actually existing cosmopolitanism. The South Atlantic Quarterly 101(4): 869-897.

Chouliaraki L (2012) The ironic spectator: Solidarity in the age of posthumanitarianism. Cambridge: Polity Press.

Della Porta D, Kriesi H and Rucht D (2009) Social movements in a globalizing world. Basingstoke: Palgrave MacMillan.

DiMaggio P, Nag M and Blei D (2013) Exploiting affinities between topic modeling and the sociological perspective on culture: application to newspaper coverage of U.S. government arts funding. Poetics 41: 570-606.

Duggan M and Brenner J (2013) The demographics of social media users - 2012. Washington: Pew Research Center

Firat AF and Dholakia N (1998) Consuming people: From political economy to theaters of consumption. London/New York: Routledge.

Goffman E (1959) The presentation of self in everyday life. New York: Anchor 
Books.

Halupka M (2014) clicktivism: a systematic heuristic. Policy \& Internet 6(2): 115-

Hannerz U (2000) Transnational connections. Culture, people, places. London:

Routledge.

Hermida A (2010) Twittering the news. Journalism Practice 4(3): 297-308.

Holt, DB (1995) How consumers consume: A typology of consumption practices.

Journal of Consumer Research 22(1): 1-16.

Honeycutt C and Herring SC (2009) Beyond microblogging: conversation and collaboration via Twitter. Proceedings of the Forty-Second Hawai' $i$

International Conference on System Sciences. Lo Alamitos, CA: IEEE Press.

Jabri V (2007) Solidarity and spheres of culture. Review of International Studies 33(4): 715-728.

Jenkins H (2004) Pop cosmopolitanism: mapping cultural flows in an age of media convergence. In: Suarez-Orozco MM and Qin-Hilliard DB (eds) Globalization: culture and education in the new millennium. Los Angeles CA: University of California Press.

Larsson AO (2013) Rejected bits of program code: why notions of "Politics 2.0" remain (mostly) unfulfilled. Journal of Information Technology \& Politics, 10(1), 72-85.

Larsson AO and Moe H (2011) Studying political microblogging: Twitter users in the 2010 Swedish election campaign. New Media \& Society 14(4): 729747.

McAdam D (1982) Political process and the development of Black insurgency, 1930-1970. Chicago, IL: University of Chicago Press.

Mihelj S, Van Zoonen L and Vis F (2011) Cosmopolitan communication online: YouTube responses to the anti-Islam film Fitna. British Journal of Sociology 62(4): 613-632.

Mohr JW and Bogdanov P (2013) Introduction - topic models: what they are and 
why they matter. Poetics 41: 545-569.

Prozorov S (2013) Pussy Riot and the politics of profanation: Parody,

performativity, veridiction. Political Studies 2013: 1-18.

Rossman G (2004) Elites, masses, and media blacklists: The Dixie Chicks

controversy. Social Forces 83(1): 61-79.

Tilly C (1984) Social movements and national politics. In: Bright C and Harding S (eds) Statemaking and national politics. Ann Arbor, MI: University of Michigan Press, 297-317.

Weenink D (2008) Cosmopolitanism as a form of capital: Parents preparing their children for a globalizing world. Sociology 42(6): 1089-1106. 


\section{Notes}

1. Several of Pussy Riot's YouTube videos have well over a million views by June 2014, e.g. Pussy Riot - Punk Prayer.

2. In $70 \%$ of all tweets, locations were provided on profiles; among these $81 \%$ can be traced to either Europe or the US.

3. A complete overview of all hashtags is available upon request.

4. References to Pussy Riot's punk music and punk performances, through which the group gained notoriety and presented its explicit political protests, remain a minor discussion topic (less than a half percentage point).

5. We also performed a separate analysis of the day preceding media events (February 3, 2014). The results show a slightly less mediatized focus and one topic demonstrating an activist cosmopolitan self - compared to the total dataset. Yet, the amount of tweets in this analysis was considerably lower, resulting in a weaker topic model. 


\section{Tables}

Table 1: Hashtag themes

\begin{tabular}{|c|c|c|c|c|c|c|}
\hline \multicolumn{3}{|c|}{ Media context } & \multicolumn{4}{|c|}{ Political context } \\
\hline Events & Celebrities & News media & Politics & Rights & Activism & Support \\
\hline $17.4 \%$ & $2.8 \%$ & $1.9 \%$ & $7.6 \%$ & $6,6 \%$ & $0,7 \%$ & $0,7 \%$ \\
\hline 1,252 & 201 & 133 & 544 & 476 & 51 & 53 \\
\hline $\begin{array}{l}\text { \#amnesty } \\
\text { \#colbert } \\
\text { \#barclays }\end{array}$ & $\begin{array}{l}\text { \#madonna } \\
\text { \#celebs } \\
\text { \#bobgeldof }\end{array}$ & $\begin{array}{l}\text { \#guardian } \\
\text { \#huffpo } \\
\text { \#nytimes }\end{array}$ & $\begin{array}{l}\text { \#putin } \\
\text { \#un } \\
\text { \#politics }\end{array}$ & $\begin{array}{l}\text { \#humanrights } \\
\text { \#freedom } \\
\text { \#lgbt }\end{array}$ & $\begin{array}{l}\text { \#feminism } \\
\text { \#activism } \\
\text { \#fightthepower }\end{array}$ & $\begin{array}{l}\text { \#noputin } \\
\text { \#heroes } \\
\text { \#gopussyriot }\end{array}$ \\
\hline \multicolumn{5}{|c|}{ \#pussyriot } & \multicolumn{2}{|l|}{$40.9 \%(2,920)$} \\
\hline \multicolumn{5}{|c|}{ Total unique hashtags } & \multicolumn{2}{|l|}{787} \\
\hline \multicolumn{5}{|c|}{ Total hashtags } & \multicolumn{2}{|l|}{7,176} \\
\hline
\end{tabular}


Table 2: 10-topic solution, unsupervised topic model, 13 highest ranked terms per topic; result after 100 iterations

\begin{tabular}{|c|c|c|c|c|c|c|c|c|c|c|}
\hline \multicolumn{6}{|c|}{ Media context } & \multicolumn{5}{|c|}{ Political context } \\
\hline & Topic 1 & Topic 2 & Topic 3 & Topic 4 & Topic 5 & Topic 6 & Topic 7 & Topic 8 & Topic 9 & Topic 10 \\
\hline 1 & Riot & Colbertreport & Riot & Riot & Pussyriot & Riot & Russia & Russian & Pussyriot & Human \\
\hline 2 & Amnesty & Putin & Pussy & Pussy & Freedom & Pussy & Pussyriot & Pussy & Prison & Speak \\
\hline 3 & Concert & Members & Interview & Watch & Fight & Amnestyconcert & Free & Riot & Members & Rights \\
\hline 4 & NYC & Olympics & Colbert & Arrested & Crowd & Jail & Prisoners & Punk & Amnestyconcert & Tour \\
\hline 5 & Pussy & Riot & Meeting & Night & Gay & Sochi & Political & Jibes & Emboldened & Pussyriot \\
\hline 6 & Madonna & Editorial & Ambassador & Show & People & Brave & Live & Women & World & International \\
\hline 7 & Barclays & NYT & Power & Great & Make & Today & Response & Band & Alyokhina & Group \\
\hline 8 & Humanrights & Board & Man & Colbert & NYTimes & Discuss & Churkin & Envoys & Afraid & Girls \\
\hline 9 & Center & Tolokonnikova & Shirtless & Scuffle & Stop & Time & Brooklyn & Trade & Terrible & Stand \\
\hline 10 & Sochi & Fun & Horse & Polite & Experience & Troublemakers & Words & Protest & Conditions & Urges \\
\hline 11 & Star & Maria & Future & Politics & Decision & USenvoy & Concert & Spoke & Nadya & United \\
\hline 12 & Studded & Nadezhda & Leading & Blondie & Appears & Video & Love & Envoy & Church & Politicians \\
\hline 13 & Freed & Pussy & Bright & Introduces & Vagina & Music & Takes & Spat & America & Honored \\
\hline
\end{tabular}

